\title{
LIBRARY MANAGEMENT SYSTEM: HOW TO AUTOMATE AND PUT A SMALL LIBRARY ONLINE
}

\author{
Tiago Lourenço ${ }^{1}$ \\ Clara Silveira ${ }^{2}$
}

DOI: https://doi.org/10.31410/LIMEN.2020.349

\begin{abstract}
Even with the amount of information that is diffused nowadays over the internet it is undeniable that the books in paper format are still a valuable source of knowledge either because they are often a reliable source or because the paper gives us a sensation that a screen does not give. Having said that, it is essential that a library not only publishes on the internet all the available books but also ensures good management for all that knowledge source. That is how this research and project comes up, a compilation of library standards for its management from the cataloguing of the books to its physical display in the library, as well as the automatization of all that standards. This study and the application of its results were done in a small library, Centro de Camoes that complements the Department of Humanities of Marie Curie-Skłodowska University in Lublin, Poland. It used the Agile software engineering methodology, a light, efficient and low risk way of development. User stories were used as an approach that promotes essentially the user's point of view in the solution, i.e lead the team to think, question and perceive what they are developing. The main features of the automatization and management system are the cataloging with a book online search script by ISBN that returns the vital intel of a book, a website that shares with the users all the bibliography available and a books manager, also includes a requisitions manager that allows warnings to the library and users. The framework used was Django, a high-level Python Web framework. On it, we apply technologies like channels, Web sockets and all the fundamental guidelines of Web development. Therefore, this article is a jump start for those who want either implement a similar solution in a library or want to apply some technologies used on this project on their own projects, the source code of this project can be found at https://github.com/tfcl/camoes.
\end{abstract}

Keywords: Library management, Web programming, Agile, User story.

\section{INTRODUCTION}

7 his article will approach research where the key concepts in the management of a library will be presented, crucial concepts in the design of a computing system that ensures more digital and automatic management of all the bibliographic content, in other words how to put a library in the XXI century.

The first sections will address the presentation of the concepts such as categorization, unique identifiers and exchange of records among libraries, in the last five sections we will present the technical details of the system such as type of users, functionalities like the requisitions manager, this technical details will be demonstrated using the UML language, including use

\footnotetext{
1 Instituto Politécnico da Guarda - ESTG, Portugal, Avenida Dr. Francisco Sá Carneiro, 50; 6300-559 Guarda; Portugal

2 Instituto Politécnico da Guarda - ESTG, Portugal, Avenida Dr. Francisco Sá Carneiro, 50; 6300-559 Guarda; Portugal
} 
cases (Jacobson, 2004). The development of this solution implemented the Extreme Programming-User Stories methodology (Rubin, 2012) that is characterized for involving the user during all the development process.

This article is intended to show the design and implementation of a software system for the management of a library.

\section{BACKGROUND}

Most of the libraries display physically the books based on classification systems, these systems allow that all the books with related subjects are ordered logically.

This method was created with the need of a systematic arrangement aiming at the improvement of the reader's experience since that is the subject of the search criteria often used by most of them.

Classification is therefore one of the most important tasks in a library because it ensures a quick search of any book, so it is based on the principle that when we find a literary work next to it we will find a related one (Barbosa, 1969).

The process of classification is rigorous, we must read the preface, the introduction as it acquires the knowledge of the book content in order to understand what subject is covered.

This process is made from the general to the particular, that is, we start from the big areas of knowledge (e.g. social sciences; Mathematics, Natural sciences) to the more specific areas (e.g. politics, Physics) (UDC, 2013).

In 1976 Melvil Dewey wrote the book, The classification and subject index for cataloging and arranging the books and pamphlets of a library, in which the classification system designed by him is described. This system, Dewey Decimal System abbreviated to DDC started to be used around the world since it was one of the first implementing a decimal classification and because it allowed the search criteria described at the beginning of this section to stand out from the classification systems available at the time for being more usable, expandable and easy to memorize (Barbosa, 1969). Nowadays it is still used, however, due to its limitations it is only reliable in libraries with a small number of books.

In 1895 the International Institute of Bibliography based on the Work of Dewey, designs the Universal Decimal Classification, abbreviated to DDC, which in the beginning were very similar, however, with the expandability that DDC offers in the sub-areas of knowledge, they are more and more different (Barbosa, 1969).

The classification system used in this project is UDC since it is widely used in Europe.

\section{Universal Decimal System}

After presenting a brief sum-up of the historical context in the previous section we proceed to explain the specificities of this classification system. This system divides the knowledge into 10 main classes, and these can be divided into subclasses, in a decimal hierarchy which ensures an infinite extension to make reading easier, a "." is placed every 3 digits. To ensure greater flexibility this system uses signs or symbols where links can be made between auxiliary 
subjects or tables where we can even specify the type of work (Barbosa, 1969). To clarify, Figure 1 shows these classes and their notations as well as auxiliary signs and numbers.

Below are listed four examples of this classification system.

Example 1: 821.9 [LANGUAGE. LINGUISTICS. LITERATURE > Literature > Literatures of individual languages and language families $>$ Literature in artificial languages]

Example 2: 7/8 [Art / Literature]

Example 3: 384 "20" [Telecommunications on the XX century]

Example 4: 5(038) $=30$ [Geology German Dictionary]

Figure 1. Classes and special Notations of UDC

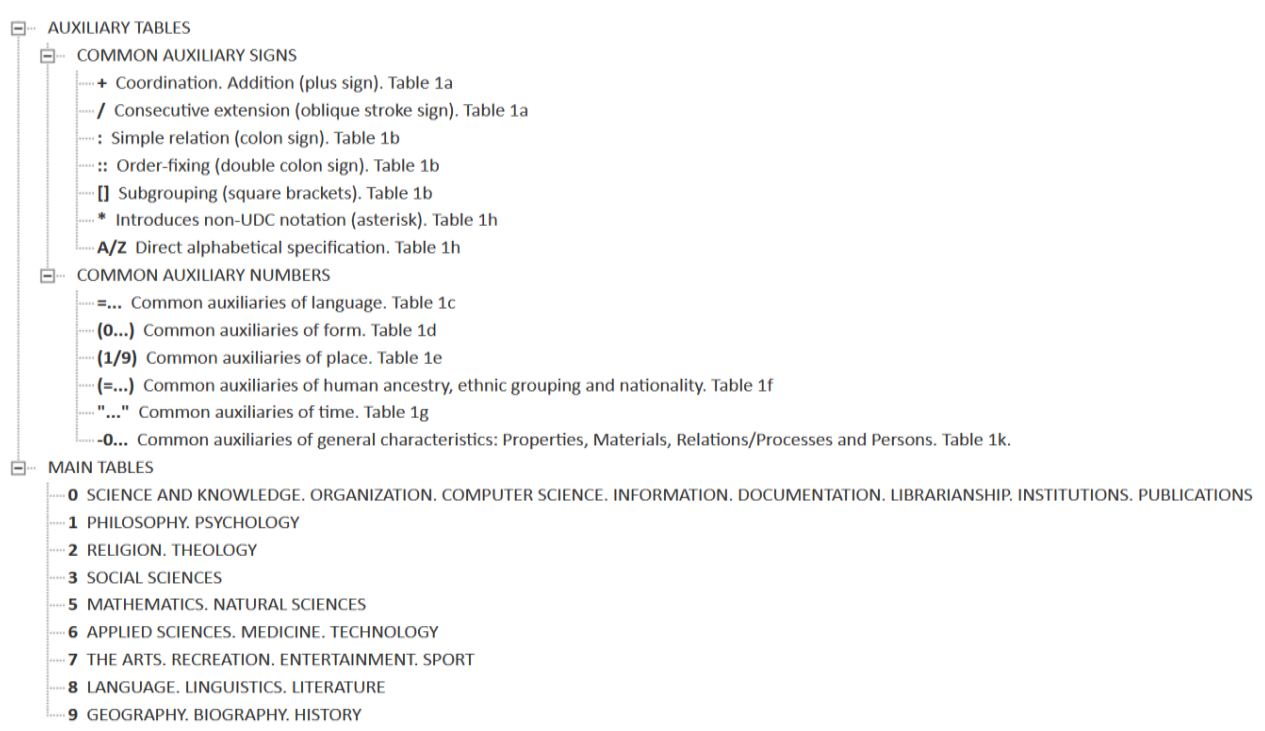

Source: http://www.udcsummary.info

\section{Exchange of Records}

If the categorization process is so rigorous and since nowadays the bibliographic data of most of the books are shared over the internet, it makes sense that we automate the process, either to minimize the error or to simplify it.

To make the exchange of records easier in the 1960s the Marc records were designed, these records contain all the data of a book and at the same time can be interpreted by a computer (Library of Congress, 2009).

The Marc records use tags so they can be machine readable, with the evolution of the Markup Languages nowadays these records are more developed as it is the case of MarcXChange that is an XML based exchange format (Biblioteca Nacional de Portugal, 2016).

There are several API's online where we can access these records, the Portuguese Government created an open data project, BNP PorData, where we can access the records of most of the books published in Portugal, it's available in http://urn.bn.pt/accesso.urn.

The other API used on this project was the WordCat, it's available in https://www.oclc.org/. 


\section{International Standard Book Number}

The International Standard Book Number abbreviated to ISBN is a unique book identifier with which we can categorize work by type of content (e.g. Book, movie), country, author, publisher. The books released after 2007 use a 13-digit format (ISBN-13) while the previous ones use a 10-digit format (ISBN-10). Since it is a standard unique book identifier, it is used worldwide for sharing bibliographic data and updating library catalogues (International ISBN Agency, 2014

\section{DEVELOPMENT OF THE LIBRARY MANAGEMENT SYSTEM}

All the code of this software and images of it can be found at this github repository https://github.com/tfcl/camoes, the solution was developed using the framework Django. Figure 2 shows the algorithm written in pseudocode to validate an ISBN.

Figure 2. ISBN Algorithm Validation

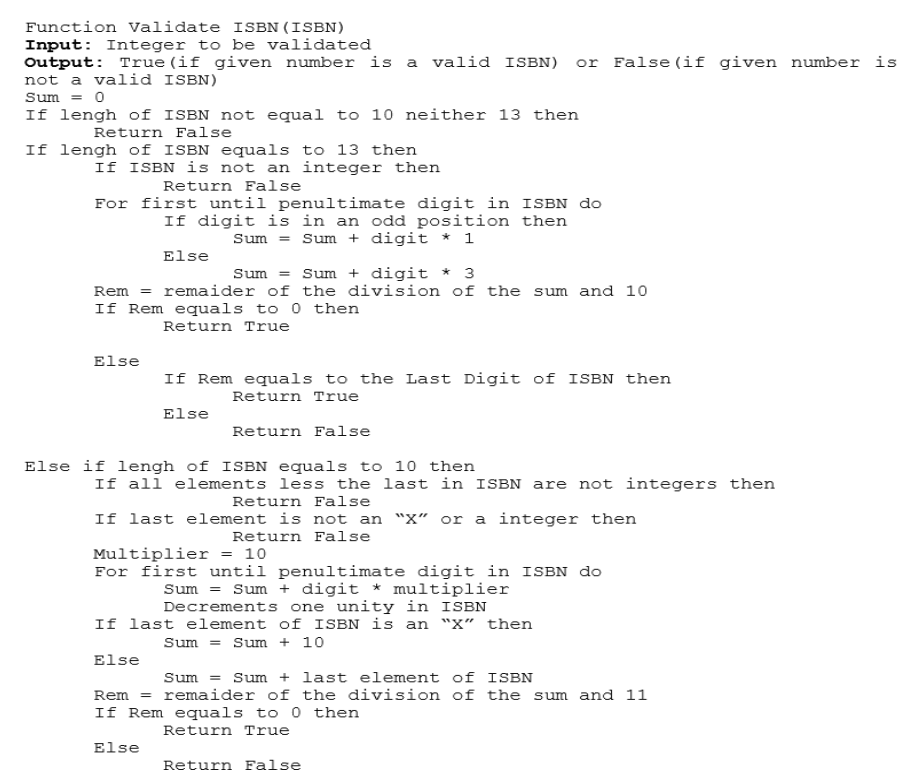

The User Stories have origin in the Extreme Programming Methodology, they describe certain features that the team is developing, these features must be valuable to the user. A User Story is described by a Story Card that is checked by a Test Case (Jacobson, Lawson, McMahon, \& Goedicke, 2019).

Figure 3. Story Cards
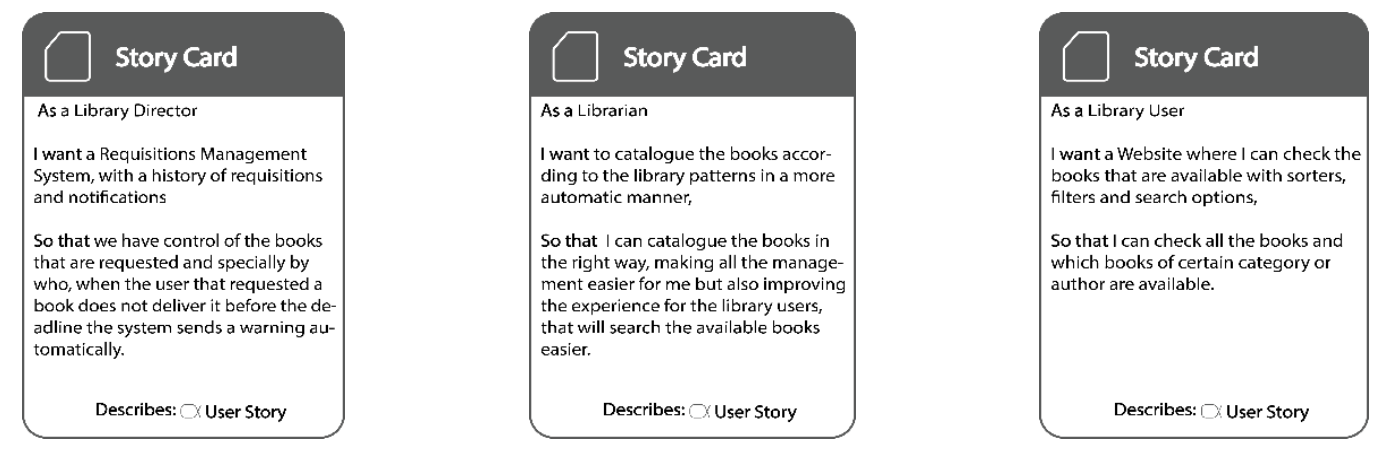
In Figure 3, three story cards are representing either the three types of users, Director of the Library, Librarian, and the library user either the features that are most valuable for each one of them.

\section{Use Cases}

In Figure 4 it is possible to have an idea of the system overall, this Figure shows the use cases, they demonstrate what each actor can do in the system as well some restrictions like the actor must be logged in the system in order to access some of the features.

Figure 4. Use Case Diagram

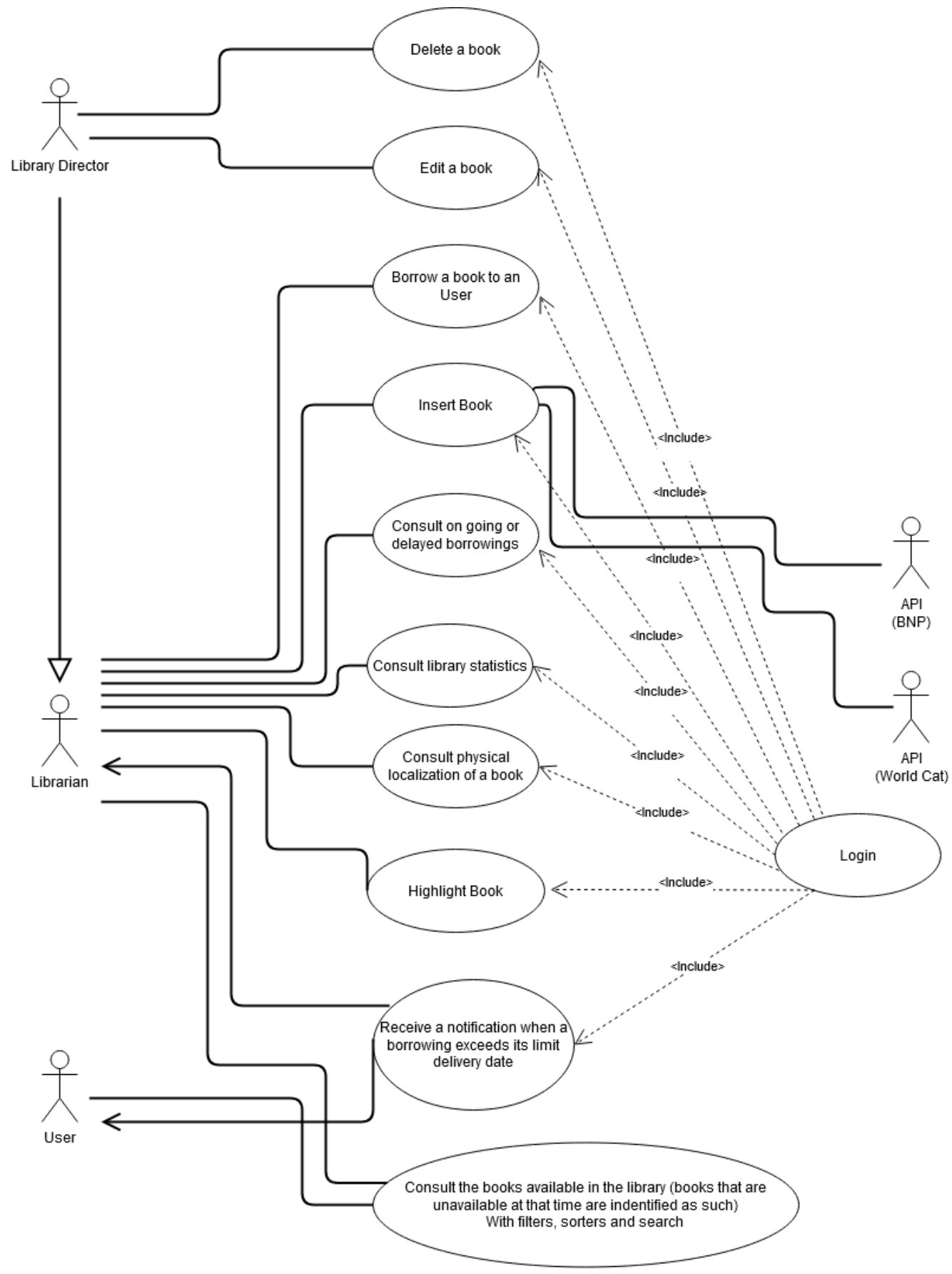


In Figure 5 we present the design of the class diagram, with which it is possible to implement the Use cases in Figure 4 and also have a more detailed view of the solution.

\section{Class Diagram}

Figure 5. Class Diagram

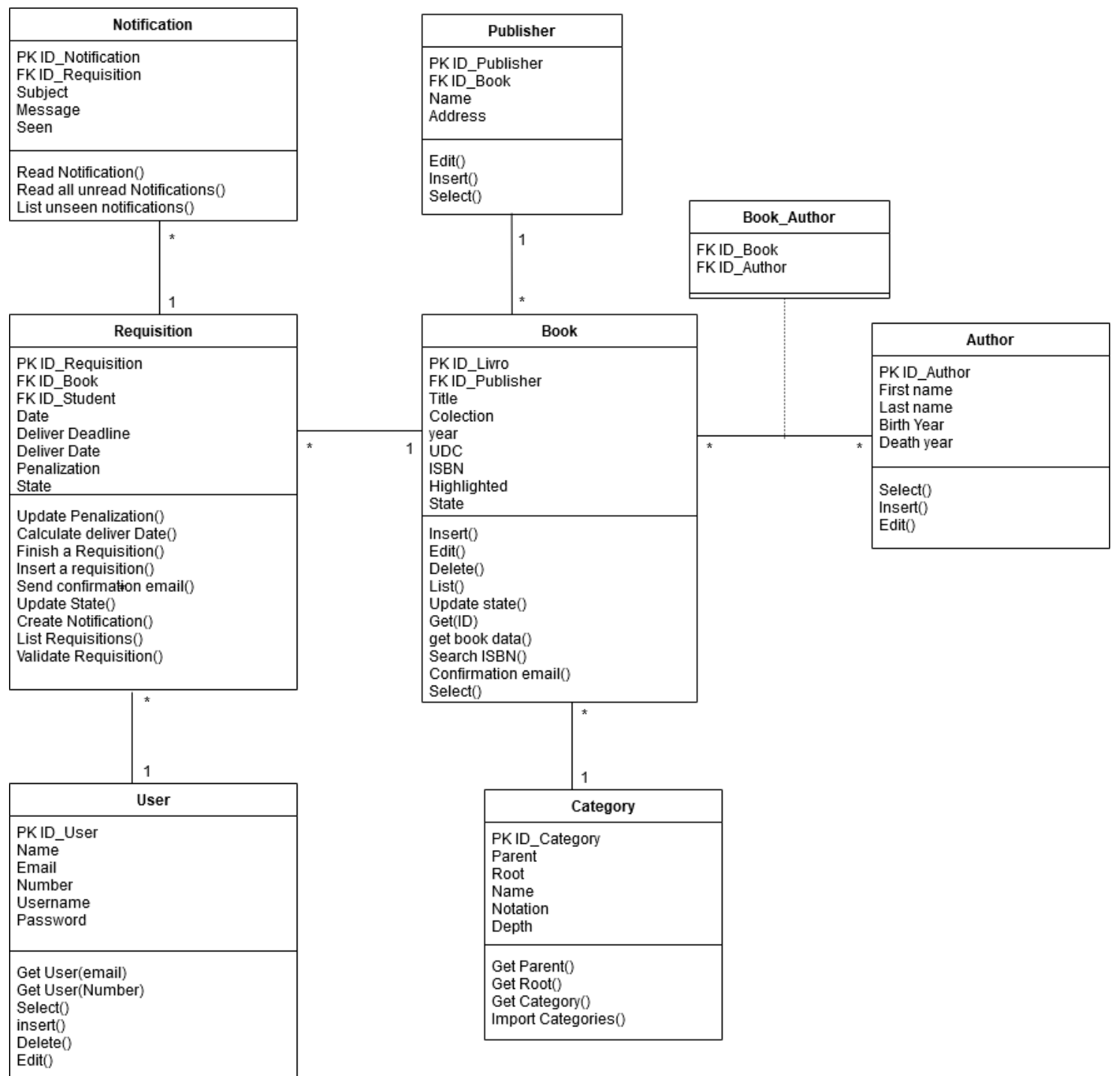

\section{Requisitions Feature}

Since the library provides a requisition service we must maintain track of them. Usually, the library users don't deliver the books, so we need a feature that can warn either the user either the library staff when a certain book it's not delivered on the agreed date. That's why we need a notification table; an entry is created when a certain book overpassed the deadline. The user is also blocked and cannot do more requisitions while he doesn't normalize his situation and cannot have more than 3 active requisitions at one time.

In this specific case after cataloguing all the books, we noticed that from 2737 books, 187 were missing, that's why this feature is so important because the books are the most valuable resource in a library and we must know where each one of them is. 


\section{FUTURE RESEARCH DIRECTIONS}

In the future, this system could implement its own online API for exchanging its records.

We could also design more features like classifications converters, an electronic Library in order to share eBooks from known writers, or most important beginners that want to give their work more visibility.

To summarize, implementing more features to share content over the internet and with us helping this community to grow.

\section{CONCLUSION}

It is not difficult, even in a small library, to lose control of the books that are arriving. It is necessary to immediately insert them into a computer system. It has been proven that currently exists several API's that besides speeding up the insertion ensures that the book is catalogued according to good practices and thus improve the experience of both, readers and librarians. It was also seen that when the library makes it possible for readers to borrow books, it is important to ensure the returns as sometimes users do not do so, thereby causing loss to the library. With this article, we show what are the key points in a library to sum up, cataloging, put the book in the right place and from then on always know where it is.

\section{REFERENCES}

Barbosa, A. P. (1969). Teoria e Prática dos Sistemas de Classificação Bibliográfica, Instituto Brasileiro de Biliografia e Documentação.

Biblioteca Nacional de Portugal. (2016). Documentation, Retrieved from https://opendata.bnportugal.gov.pt/eng_documentation.htm.

International ISBN Agency. (2014). What is an ISBN?, Retrieved from https://www.isbninternational.org/content/what-isbn

Jacobson, I. (2004). Use Cases - Yesterday, Today, and Tomorrow; Software and Systems Modeling; Vol. 3, № 3, pp. 210-220.

Jacobson, I., Lawson, H., McMahon, P., \& Goedicke, M. (2019). The Essentials of Modern Software Engineering, ACM Books.

Library of Congress. (2009). What is a Marc Record, and Why is it Important?, Retrieved from https://www.loc.gov/marc/umb/um01 to06.html.

Rubin, K. (2012). Essential Scrum: A Practical Guide to the Most Popular Agile Process. Addison-Wesley Professional.

UDC. (2013). Universal Decimal Classification, Retrieved from http://www.udcsummary.info/php/index.php. 